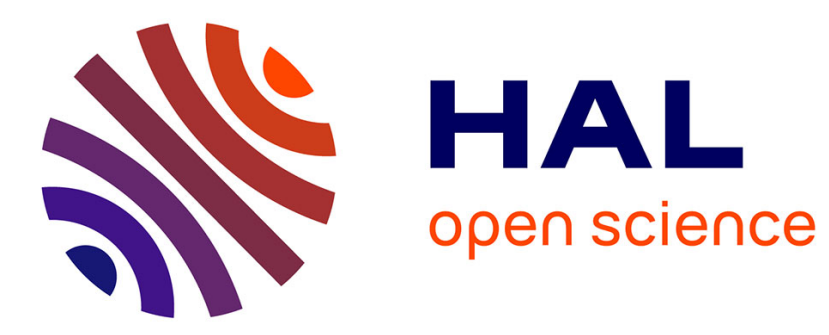

\title{
Thermodynamic exploration of xenon/krypton separation based on a high-throughput screening
}

Emmanuel Ren, François-Xavier Coudert

\section{To cite this version:}

Emmanuel Ren, François-Xavier Coudert. Thermodynamic exploration of xenon/krypton separation based on a high-throughput screening. Faraday Discussions, 2021, 231, pp.201-223. 10.1039/D1FD00024A . hal-03189895

\section{HAL Id: hal-03189895 \\ https://hal.science/hal-03189895}

Submitted on 5 Apr 2021

HAL is a multi-disciplinary open access archive for the deposit and dissemination of scientific research documents, whether they are published or not. The documents may come from teaching and research institutions in France or abroad, or from public or private research centers.
L'archive ouverte pluridisciplinaire HAL, est destinée au dépôt et à la diffusion de documents scientifiques de niveau recherche, publiés ou non, émanant des établissements d'enseignement et de recherche français ou étrangers, des laboratoires publics ou privés. 


\title{
Thermodynamic exploration of xenon/krypton separation based on a high-throughput screening ${ }^{\dagger}$
}

\author{
Emmanuel $\operatorname{Ren}^{a b}$ and François-Xavier Coudert ${ }^{* a}$
}

\begin{abstract}
Nanoporous framework materials are a promising class of materials for energy-efficient technology of xenon/krypton separation by physisorption. Many studies on $\mathrm{Xe} / \mathrm{Kr}$ separation by adsorption have focused on the determination of structure/property relationships, the description of theoretical limits of performance, and the identification of top-performing materials. Here, we provide a study based on a highthroughput screening of the adsorption of $\mathrm{Xe}, \mathrm{Kr}$, and $\mathrm{Xe} / \mathrm{Kr}$ mixtures in 12,020 experimental MOFs materials, to provide a better comprehension of the thermodynamics behind $\mathrm{Xe} / \mathrm{Kr}$ separation in nanoporous materials and the microscopic origins of $\mathrm{Xe} / \mathrm{Kr}$ selectivity at both low and ambient pressure.
\end{abstract}

\section{Introduction}

In the past decade, large-scale computational screening studies have become an important part of the materials science innovation pipeline, $\frac{1 \mid 2}{2}$ trying to move beyond the serendipitous model of materials discovery. $\frac{\sqrt[3]{4}}{}$ High-throughput computational discovery techniques are used in the generation of novel hypothetical structures for screening, $\frac{5[6}{6}$ as well as in trying to explore more in depth and more systematically the materials whose structure has already been published, in order to map their physical and chemical properties. ${ }^{7.9}$ While the idea of large-scale exploration of materials is not new, and such databases - whether experimental or computational in the source of their data - have been around for several decades now,,$[12]$ this field has recently seen a rapid expansion enabled by several factors.

The first factor is the growth of public, open databases of materials structures (and sometimes properties). ${ }^{13}$ To give only one example, projects like the Materials Genome Initiative have 14 15 integrated theory, computation, synthesis, and characterization that led to the generation of vast materials datasets. 16.17 Secondly, advances in the methods for construction of hypothetical structures for complex supramolecular assemblies have led to the creation of large-scale databases of hypothetical structures. 6/18[19 Thirdly, text and data mining are allowing to augment databases with content previously thought not being machine-readable and indexable, for example by identifying unreported properties of materials in older scientific papers. $\frac{2021}{21}$ Finally, the use of artificial intelligence techniques, such as statistical learning, $\frac{22}{\text { can }}$

\footnotetext{
${ }^{a}$ Chimie ParisTech, PSL University, CNRS, Institut de Recherche de Chimie Paris, 75005 Paris, France; E-mail: fx.coudert@chimieparistech.psl.eu

${ }^{b}$ CEA, DES, ISEC, DMRC, University of Montpellier, Marcoule, F-30207 Bagnols-surCèze, France.

$\dagger$ Electronic Supplementary Information (ESI) available: Additional correlation plots, isotherms and structures of selected materials.
}

enable in some cases by several orders of magnitude the scale of databases that can be screened. 23.25

Among the properties that have been studied by highthroughput screening, we can cite mechanical properties, 26.27 thermal properties, 28/29 electronic structure, 30 chemical and catalytic activity, $\frac{33,35}{35}$ among many others. One area of particular interest has been that of the exploration of nanoporous materials for fluid separation (as molecular sieves) and gas storage. 36 This has been one of the early applications of high-throughput computational screening, and it has seen an important focus because of the large number of novel frameworks discovered experimentally, which have not always been thoroughly characterized beyond the determination of their structure and their nitrogen adsorption isotherm. Moreover, adsorption-based gas separation is an important technological driver, with existing large industrialscale application for several gases, and yet with opportunities for further improvement. 40

One specific property that is highly sought after in nanoporous materials is efficient noble gas separation, and in particular $\mathrm{Xe} / \mathrm{Kr}$ separation processes. Both xenon and krypton are difficult to separate and expensive, due to their rarity and the high cost of the cryogenic distillation process that is used to obtain them commercially. 41 They are valuable for applications in lighting (flash lamps, arc lamps, and fluorescent lamps) as well as medicine (as anesthetic, for doping in sports, and imaging). 42 Here we focus on the question of xenon/krypton separation by adsorption in nanoporous framework materials, which has been cited as a possible alternative to cryogenic distillation to lower the cost of pure xenon. We aim to better understand the thermodynamics behind the $\mathrm{Xe} / \mathrm{Kr}$ separation in a large diversity of nanoporous materials, using a high-throughput screening method not to identify a small number of "top performing" materials but to determine trends and bring insight into the general effects involved. 


\section{Current state of the art}

\subsection{Reviews of the topic}

In this section we intend to give a quick overview of the current state of the art in the field, upon which we built our study, as well as highlight some of the most recent work and perspectives. This is by no means a comprehensive review, as there have already been several on the topic. Banerjee et al. ${ }^{45}$ put the topic of $\mathrm{Xe} / \mathrm{Kr}$ separation by adsorption in MOFs in the broader perspective of industrially proposed pathways for $\mathrm{Xe} / \mathrm{Kr}$ removal and capture. Their review provides an interesting high-level overview of the development of $\mathrm{Xe} / \mathrm{Kr}$ separation technologies in the specific context of used nuclear fuel reprocessing. In a later piece, 41 these authors focused more specifically on recent advances afforded by the use of MOFs materials as adsorbents for noble gas adsorption and separation. They discuss in detail the role of computer simulation in finding optimal materials for Xe adsorption, in light of rising global demand for applications in electronics, lighting, and the medical industry.

Focusing more on the larger process of digital materials discovery, and the role of large databases in materials research, 46 Boyd et al. $\frac{47}{}$ provide a broad review of the computational developments involved in the nanoporous materials genome research effort. They show that a large number of high-throughput screening studies have been targetted specifically at the question of gas phase separation, with a range of different adsorbate molecules going from noble gases, small molecules (both apolar and polar), to short alkanes and aromatics. Both Adil et al. $\frac{48}{48}$ and Sturluson et al. ${ }^{49}$ provide general reviews on the modelling in MOFs for gas separation and storage, and structure/separation relationships in MOFs for gas separation, featuring specific sections to the still open problem of $\mathrm{Xe} / \mathrm{Kr}$ separation.

Very recently, Daglar et al. $[50$ reviewed high-throughput computational screening of MOF materials for gas separations, showing that most studies in the field - especially those at larger scale - have focused primarily on thermodynamic data based on single-component properties, and in particular low-pressure selectivity and saturation uptake. In a series of case studies on the $\mathrm{Xe} / \mathrm{Kr}$ separation at low concentration, Montpezat et al. $\underline{51}$ demonstrated the important limitations of relying on the IAST model and approaches based on the Henry's constants, especially for very low concentrations. This is part of what prompted us to look further into the thermodynamics of $\mathrm{Xe} / \mathrm{Kr}$ separation, in a systematic manner.

\subsection{MOFs for rare gas and $\mathrm{Xe} / \mathrm{Kr}$ adsorption-based separa- tion}

Metal-organic frameworks, and later other supramolecular porous materials like covalent organic frameworks (COFs), have been proposed for applications in separation of noble gases for a decade. With no aim of being exhaustive, we highlight some of the milestones in that area, both from experimental and computational point of view.

In 2012, Liu et al. 53 published an experimental study of two MOFs, HKUST-1 and Ni/DOBDC, for adsorption of Xe and $\mathrm{Kr}$ at ppm (part-per-million) levels in air. The target application was the removal of $\mathrm{Xe}$ and $\mathrm{Kr}$ from nuclear fuel reprocessing plants. The same group later proposed a two-column method for the separation of $\mathrm{Kr}$ and Xe from process off-gases ${ }^{54}$, based on MOF materials. At about the same time, Bae et al. ${ }^{55}$ combined a computational Grand Canonical Monte Carlo (GCMC) study with experimental breakthrough measurements of the separation of a Xe/Kr mixture on MOF-505 and HKUST-1.

Parkes et al. 56 studied sixteen different MOF materials for $\mathrm{Kr}$, Ar, and $\mathrm{N}_{2}$ adsorption and separation, through GCMC simulations. They concluded on the potential of MOFs for separation, and a general correlation between the Henry's constant and the isosteric heat of adsorption for the three gases studied. A year later, in 2014, Chen et al. $\frac{57}{}$ demonstrated, again through a combined computational and experimental study, the potential of porous organic cages for selective binding of xenon over krypton.

Later experimental work expanded these early separation studies to different types of MOF materials. Xiong et al. $[58$ studied a flexible zinc tetrazolate framework for xenon selective adsorption over krypton, argon and nitrogen. Thermodynamic analysis of the adsorption isotherms at various temperatures confirmed the occurrence of a "breathing" structural transition upon Xe uptake, contributing to a high working capacity for a pressure swing adsorption (PSA) cycle. Lee et al. $\frac{59}{59}$ compared the selective adsorption properties for $\mathrm{Xe} / \mathrm{Kr}$ mixtures on three highly-studied MOFs, namely UiO-66(Zr), MIL-100(Fe) and MIL-101(Cr), and confirmed a high potential of $\mathrm{UiO}-66(\mathrm{Zr})$ for separations under dynamic flow conditions. These authors also assessed the hydrothermal and radioactive stability of the material, a test seldom performed in the existing literature, and found it to be good. In a further study, 60 they demonstrated that $\mathrm{Xe} / \mathrm{Kr}$ selectivity could be further improved by ligand substitution.

In parallel, computational studies were published to provide insight at the microscopic level into the mechanisms behind good (and bad) separation properties. Wang et al. 61 studied 6 MOFs and COFs for adsorption of $\mathrm{Xe}$ and $\mathrm{Xe} / \mathrm{N}_{2}$ separation, through GCMC simulations looking at the impact of pressure (and therefore pore filling) on selectivity. Anderson et al. 62 combined GCMC and biased MD simulations to elucidate the nature of adsorption- and diffusion-based $\mathrm{Kr}$ /Xe separation mechanisms in four archetypal nanoporous materials: SAPO-34, ZIF-8, UiO66 , and IRMOF-1. These authors draw a couple of general conclusions, including the fact that diffusion selectivity for krypton dominates membrane separation selectivity, and large pore cages and stiff pore windows are desirable - however the scope of these conclusions is inherently limited by the small number of materials actually studied.

In a different family of materials, Tong et al. $\frac{63}{6}$ have surveyed the structure-property relationships of covalent organic frameworks (COFs) for noble gas separation, by GCMC simulations of 187 different materials for $\mathrm{Kr} / \mathrm{Ar}, \mathrm{Xe} / \mathrm{Kr}$ and $\mathrm{Rn} / \mathrm{Xe}$ separations. These authors included in their calculations some adsorption figures of merit (AFM), representative of the conditions of industrial vacuum (VSA) and pressure swing adsorption (PSA) processes.

One area that has been particularly explored is the tuning and improvement of separation properties through the presence and nature of coordinatively unsaturated sites (or open metal sites) in 

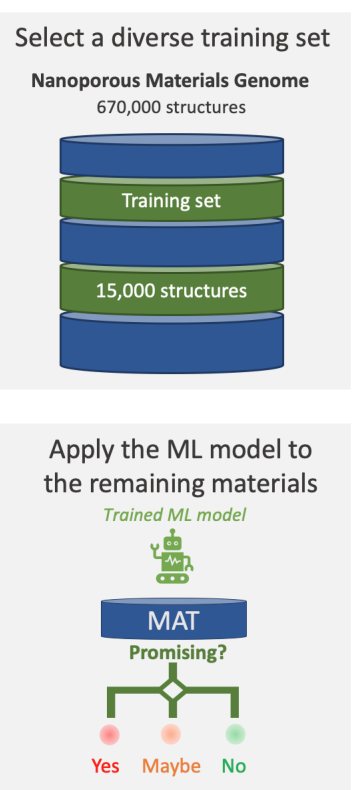
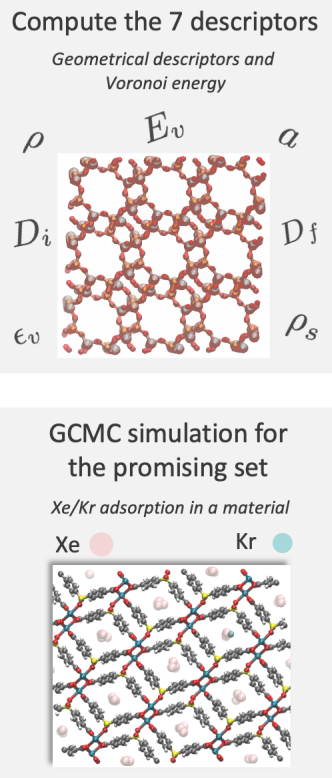
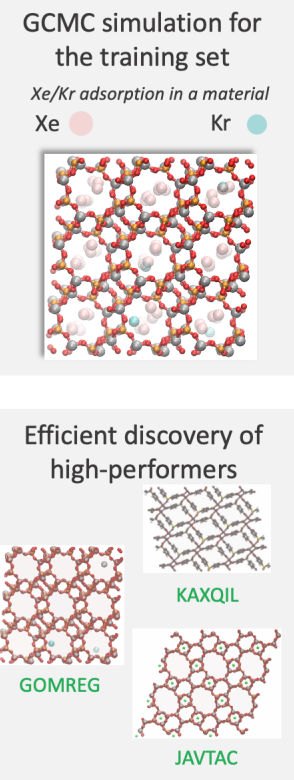

Train a random forest

regressor model

Optimisation of the loss function

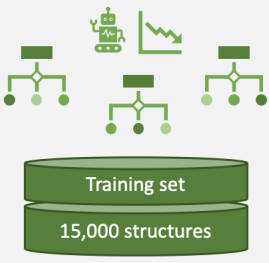

Assess the performance of

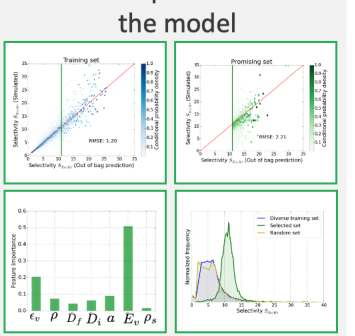

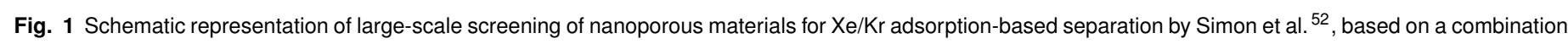

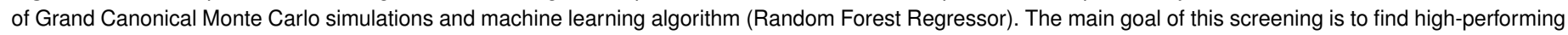

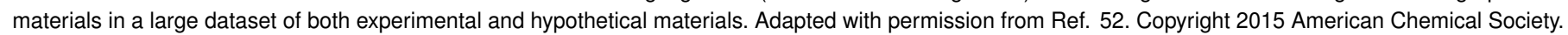

MOFs. In 2016, Vazhappilly et al. 64 used density functional theory (DFT) calculations of host-guest binding energies to probe the impact of the metal atoms in a specific framework (MOF-74) on $\mathrm{Xe}$ and $\mathrm{Kr}$ adsorption. Later, Zarabadi-Poor et al. 65 investigated - again through computational methods - a series of metal-BTC MOFs for recovering xenon from exhaled anesthetic gas, i.e., mixtures of $\mathrm{CO}_{2}, \mathrm{O}_{2}$, and $\mathrm{N}_{2}$.

\subsection{Recently-proposed candidates for separation}

Several very recent experimental reports used the strategy outlined above to improve separation properties, as well as tuning the chemical nature of the organic linkers. Tao et al. 66 looked at tuning (and improving) the selective adsorption of Xe over Kr by MOF open metal sites in the UTSA-74 framework structure. Idrees et al. 67 designed a new zirconium-based MOF, NU403, based on a three-dimensional linker: bicyclo[2.2.2] octane1,4-dicarboxylic acid. The linker dimensionality and MOF pore aperture were found to dramatically improve the $\mathrm{Xe} / \mathrm{Kr}$ separation, as did postsynthetic defect healing. Finally, Zhang et al. 68 showed that a strategy of decoration of the internal pore surface with polar groups could fine-tune the separation properties in ultramicroporous MOFs: they modified the MIL-120 material by introducing hydroxyl groups, increasing the $\mathrm{Xe} / \mathrm{Kr}$ selectivity.

In 2019, Li et al. 69 proposed a rigid squarate-based MOF with "perfect pore size" (comparable with the kinetic diameter of Xe), and an internal pore surface decorated with very polar hydroxyl groups. This material demonstrated record-high $\mathrm{Xe} / \mathrm{Kr}$ selectivity of 60.6 at low pressure ( 0.2 bar) at ambient temperature. Last year, Xiong et al. ${ }^{70}$ identified the ultramicroporous calcium-based MOF UTSA-280, which was also selected based on geometrical arguments of pore size, as having very high $\mathrm{Xe} / \mathrm{Kr}$ selectivity.

\subsection{Large-scale screening}

In the work described above, both experimental and computational, researchers tried to identify MOFs for $\mathrm{Xe} / \mathrm{Kr}$ separation by chemical intuition or small-scale screening studies. But highthroughput computational methods have also been used, in the form of larger-scale screening studies, which we will describe in this section.

The first high-throughput screening study of MOF-type materials for $\mathrm{Xe} / \mathrm{Kr}$ adsorption-based separation was published by Sikora et al. in 2012. 44 This followed the seminal work of the same group ${ }^{5}$ for the computational generation of hypothetical metal-organic framework structures from a given chemical library of organic and inorganic building blocks. Wilmer et al. have subsequently used those hypothetical structures as a basis for screening of adsorption properties, to identify promising MOF structures and uncover structure-property relations, 71 targeting properties such as methane storage capacity, ${ }^{5}$ Brunauer-EmmettTeller (BET) surface area, 72 etc. Applying this methodology to Xe and $\mathrm{Kr}$ adsorption, Sikora et al. used multi-component GCMC simulations to calculate the $\mathrm{Xe} / \mathrm{Kr}$ selectivity on a library of 137,000 structurally diverse hypothetical MOFs. Their focus in this study was two-fold: first, they aimed at establishing the possible performance limits for $\mathrm{Xe} / \mathrm{Kr}$ adsorptive separation in MOFs; secondly, they correlated the $\mathrm{Xe} / \mathrm{Kr}$ selectivity with geometrical features of the host frameworks. They confirmed that cavities with a size larger than, but not more than twice, that of a xenon atom generally had the highest selectivity - showing that pore morphologies resembling tubes of uniform width are apparently favourable.

In 2015, Simon et al. $\frac{52}{}$ analyzed the Nanoporous Materials Genome, $47 / 73$ a database of about 670,000 experimental and hypothetical porous material structures, including MOFs, zeolites, PPNs, ZIFs, and COFs, for candidate adsorbents for 
xenon/krypton separations. It is possibly the largest-scale study performed in this area, both by the sheer number of frameworks involved and by the diversity of their nature. Because such a set is too big for brute-force screening with GCMC simulations, they proposed a multi-scale modelling strategy combining machine learning algorithms (trained on a diverse subset of 15,000 materials) with molecular simulations (used both to generate the ML training data, and to refine the separation properties for the top performers obtained by the ML predictor). Without going into details (see Fig. 1 for more details), the ML model they trained was mainly based on geometric structural descriptors, with the addition of a single energy-based descriptor: the Voronoi energy (i.e. the average energy of a xenon atom at the accessible nodes in the Voronoi partition of space). In addition to identifying and describing some top performing materials, the authors also analyzed the correlations between high $\mathrm{Xe} / \mathrm{Kr}$ selectivity and the geometric properties of the frameworks, in order to "rationalize the strong link between pore size and selectivity". In particular, by developing theoretical pore models of spherical and cylindrical geometries, they could highlight the general geometrical trends observed, but also the fact that there is a wide diversity of performance beyond the geometrical features of the frameworks.

Guo et al. 74 have followed an unusual approach, with an intermediate-scale screening based on a lower-accuracy methodology for the description of host-guest interactions, namely the classical density functional theory. Looking at noble gas adsorption/separation from 4,764 real adsorbents and 1,200 hypothetical adsorbents, they identified general trends by comparing selectivities with other adsorption properties (such as saturation uptake), as well as geometrical characteristics of the materials (such as surface area, void fraction and pore size).

There are also several examples in the published literature where $\mathrm{Xe} / \mathrm{Kr}$ selectivity is studied not as the sole focus of a paper, but as one of several example applications of a broader methodological development. In 2017, Colón et al. 75 used a topologically guided algorithm to automate the construction of 13,512 hypothetical MOF frameworks featuring 41 different topologies. Among other figures of merit, they evaluated these materials for adsorption-based separation of xenon/krypton mixtures at various operating conditions through GCMC simulations. Like the studies described above, these authors looked to link the $\mathrm{Xe} / \mathrm{Kr}$ selectivity with topology and geometrical properties, such as largest cavity diameter. Similarly, in their 2019 update of the Computation-Ready, Experimental Metal-Organic Framework ("CoRE MOF") database, Chung et al. ${ }^{76}$ included a short demonstration of a screening study on $\mathrm{Xe} / \mathrm{Kr}$ separation. There, they focused on the impact of bound solvent removal on the Xe/Kr adsorption performance, and showed in particular that the removal of coordinated water molecules could strongly (and negatively) impact the xenon affinity of nanoporous materials.

\subsection{Context of the present work}

As we have seen above in the existing literature, the computational screening of the nanoporous materials - both existing frameworks and hypothetical structures - for targeted adsorp- tion properties has been the object of many studies, and several of those high-throughput screening studies have focused on noble gas separation, and $\mathrm{Xe} / \mathrm{Kr}$ separation, in particular. For large-scale studies we have found that, in addition to the testing and validation of methodological developments, the screening aimed in most cases at one of three objectives: (i) to identify top performing materials for synthesis and/or characterization; (ii) to better understand the limits of possible performance, and the relationships and trade-offs between various metrics of performance (selectivity, uptake, etc); (iii) identify structure-property relationships, correlating separation performance with structural properties of the materials that can be more easily determined (i.e., at low computational cost).

In the present work, our goal is not directly to address the structure-property relationships, but rather to map out the details of the thermodynamic features of $\mathrm{Xe} / \mathrm{Kr}$ adsorption and separation in nanoporous materials. We used the high-throughput screening methodology as a way to map out the space of thermodynamic properties, going beyond the usual quantities of selectivity and uptake, to focus more specifically on the role of adsorption enthalpy and entropy, the differences between Xe and $\mathrm{Kr}$ adsorption thermodynamics, and the differences between selectivity at low and high pressure.

\section{Computational methods}

\subsection{Simulations}

We used two Monte Carlo-based simulation methods to systematically investigate the thermodynamics behind the separation properties of MOF materials: (i) Widom insertion simulations of pure components (with $10^{5}$ steps for each material and adsorbate) to probe the $\mathrm{Xe} / \mathrm{Kr}$ selectivity at very low pressure; (ii) multi-component GCMC simulations (with $10^{5}$ steps for each material and thermodynamic condition) to compare those results to standard conditions of separation (20:80 and 90:10 mixtures in $\mathrm{Xe}$ and $\mathrm{Kr}$ ) at $298 \mathrm{~K}$ and $1 \mathrm{~atm}$. In addition, to investigate in detail some specific materials, we performed full pure-component isotherm calculations (see Section 4.4).

All simulations were done using the RASPA software package, 77 with the nanoporous frameworks considered as rigid. Lennard-Jones (LJ) truncated and shifted potentials with a $12 \AA$ cut-off without tail corrections were used to model the van der Waals interactions between atoms. While the choice of force field is known to impact the prediction of gas adsorption (and therefore separation selectivity) for each specific material, our goal here is to address statistically the thermodynamics of the adsorption and separation processes. LJ parameters for Xe and $\mathrm{Kr}$ were taken from their definition in the RASPA GenericMOFs force field, where the values of the LJ well depth $(\varepsilon)$ and the LJ diameter $(\sigma)$ are respectively: $\varepsilon_{\mathrm{Xe}}=221.0 \mathrm{~K}$ and $\varepsilon_{\mathrm{Kr}}=116.4 \mathrm{~K}$, and $\sigma_{\mathrm{Xe}}=4.100 \AA$ and $\sigma_{\mathrm{Kr}}=3.636 \AA$. The LJ parameters of the atoms of the host framework were taken from the universal force field (UFF). 78 The Lorentz-Berthelot combination rules were used to determine cross interaction parameters between different atoms. 79 The Peng-Robinson equation of state was used to compute fugacity coefficients used to determine the chemical potential of 
the system (in GCMC calculations). $\sqrt[80]{ }$ Potential energy interpolation grids with $0.1 \AA$ spacing were precalculated to speed-up the simulations.

\subsection{Database}

Chung et al. proposed a new Computation-Ready, Experimental MOF database (CoRE MOF 2019) containing over 14,000 cleaned structures. 76 The structures originated from the Cambridge Structural Database and Web of Science search. These structures went through a curation process: (i) by removing coordinates with low partial occupancies, (ii) by converting the structure to P1 symmetry, (iii) by removing free solvents (i.e., free solvent removed FSR), (iv) also removing bound solvent molecules (i.e., all solvent removed ASR), then (v) by restoring semi-automatically some disordered structures using a crystal generator. After this process, the structures are said to be "clean".

In this study, we used the 12,020 structures of the CoRE MOF 2019-ASR (all solvent removed) database that are publicly available. Then, we extracted the non-disordered structures and the structures with a cell volume smaller than $20 \mathrm{~nm}^{3}$ (to limit the overall calculation time). This resulted in a total of 9,668 remaining structures included in our systematic simulations to compare their selectivity and other thermodynamic quantities such as enthalpy and entropy at different pressures and compositions.

\subsection{Thermodynamic quantities}

By using Widom's insertion method, the excess chemical potential induced by a single probe adsorbate is used to determine the free energy related to the Henry's constant $K .81$ A selectivity $s_{0}=K^{\mathrm{Xe}} / K^{\mathrm{Kr}}$ is deduced from the Henry's constants of xenon $K^{\mathrm{Xe}}$ and krypton $K^{\mathrm{Kr}}$. An enthalpy of adsorption associated to a guest ( $\mathrm{g}$ ) in a given host $\Delta_{\mathrm{ads}} H_{0}^{\mathrm{g}}$ at infinite dilution is also calculated using the average guest-host interaction energy $\left\langle U_{\mathrm{gh}}\right\rangle$ and the average guest-guest interaction energy $\left\langle U_{\mathrm{gg}}\right\rangle$ from the simulations: $\Delta_{\mathrm{ads}} H_{0}^{\mathrm{g}}=\left\langle U_{\mathrm{gh}}\right\rangle-\left\langle U_{\mathrm{gg}}\right\rangle-R T$ in a rigid framework. From the Henry's constant $K$ and the enthalpy of adsorption $\Delta_{\text {ads }} H_{0}$, we can then calculate the entropy of adsorption $\Delta_{\text {ads }} S_{0}$ associated to the adsorption in the limit of low loading ( $c f$. supplementary information, Figure S2).

Multi-component GCMC calculation simulates the nanoporous material in equilibrium with a gas with a given composition and pressure. From the values of mole fraction of xenon $y^{\mathrm{Xe}}$ and of krypton $y^{\mathrm{Kr}}$ in the surrounding gas and the loadings of xenon $q^{\mathrm{Xe}}$ and of krypton $q^{\mathrm{Kr}}$ inside the material, we can obtain the selectivity at ambient pressure $s_{1}=\left(y^{\mathrm{Kr}} q^{\mathrm{Xe}}\right) /\left(y^{\mathrm{Xe}} q^{\mathrm{Kr}}\right)$. The enthalpy $\Delta_{\mathrm{ads}} H_{1}^{\mathrm{g}}$ associated to a given guest $g$ is obtained using the following fluctuation formula:

$$
\Delta_{\mathrm{ads}} H_{1}^{\mathrm{g}}=\frac{\langle U \times N\rangle_{\mu}-\langle U\rangle_{\mu}\langle N\rangle_{\mu}}{\left\langle N^{2}\right\rangle_{\mu}-\langle N\rangle_{\mu}^{2}}-R T
$$

where $U$ refers to the total energy of the host and the adsorbed molecules $g, N$ the number of adsorbed molecules $g$ and $\langle\ldots\rangle_{\mu}$ refers to the averages in the grand canonical ensemble.

\subsection{Exchange equilibrium}

In order to analyze thoroughly the thermodynamics of competitive xenon and krypton adsorption using the results of both purecomponent and multi-component GCMC simulations, we use in this work some thermodynamic properties (enthalpy and entropy in various conditions) associated with the following fictitious "exchange equilibrium":

$$
\mathrm{Xe}_{(\mathrm{g})}+\mathrm{Kr}_{(\mathrm{ads})} \rightleftharpoons \mathrm{Xe}_{(\mathrm{ads})}+\mathrm{Kr}_{(\mathrm{g})}
$$

The equilibrium constant associated to the Equation (2) at a pressure of $1 \mathrm{~atm}$ for a given composition is simply the selectivity $s_{1}$, defined above as a function of $y^{\mathrm{Xe}}, y^{\mathrm{Kr}}, q^{\mathrm{Xe}}$ and $q^{\mathrm{Kr}}$, respectively the mole fractions in the gas phase and the loadings in the material of xenon and krypton in the GCMC calculation. The enthalpy difference associated with this "exchange" equilibrium, $\Delta_{\text {exc }} H_{1}=\Delta_{\text {ads }} H_{1}^{\mathrm{Xe}}-\Delta_{\mathrm{ads}} H_{1}^{\mathrm{Kr}}$, is defined as the difference of enthalpy between xenon and krypton within the mixture. Similarly, an entropy difference $\Delta_{\text {exc }} S_{1}$ can then be calculated as in Equation 3 (with $i=1$ ):

$$
\Delta_{\text {exc }} S_{\mathrm{i}}=R \ln \left(s_{\mathrm{i}}\right)+\frac{1}{T} \Delta_{\mathrm{exc}} H_{\mathrm{i}} \quad \text { where } i \in\{0,1\}
$$

Furthermore, this "exchange equilibrium" can be generalised to the zero loading limit. A comparison of the thermodynamic quantities between the low pressure and ambient pressure cases is made possible by considering this equilibrium equation. The equilibrium constant at low pressure similarly corresponds to $s_{0}$, the enthalpy to $\Delta_{\text {exc }} H_{0}=\Delta_{\text {ads }} H_{0}^{\mathrm{Xe}}-\Delta_{\mathrm{ads}} H_{0}^{\mathrm{Kr}}$ and the entropy to $\Delta_{\mathrm{exc}} S_{0}$ as written in Equation 3 (with $i=0$ ).

\section{Results and discussion}

\subsection{Statistical distribution of thermodynamic properties}

To evaluate the performance of a given nanoporous material for separation in the low loading (or low pressure) limit, Henry's constants are often calculated from linear fits of low-pressure adsorption isotherm data - both experimentally and computationally. In this section, we investigate the thermodynamics of Xe and $\mathrm{Kr}$ adsorption at low pressure. Here, We have calculated the low-pressure adsorption properties by using the Widom insertion method ${ }^{81 / 82}$ on 9,668 structures from the dataset selected. It has higher accuracy than the fitting of isotherms, where it can be difficult to know what the extent of the linear adsorption regime is. With these simulations, we could obtain for each material the Henry's constant $K$ and the adsorption enthalpy $\Delta_{\text {ads }} H_{0}$ (at the zero loading limit) for both xenon and krypton. The Xe/Kr thermodynamic selectivity $s_{0}$ in the low-pressure limit is then determined by the ratio $s_{0}=K^{\mathrm{Xe}} / K^{\mathrm{Kr}}$ of the Henry's constants for the two gases. In the following, we look at the statistical relationships between the thermodynamic quantities at low pressure: $s_{0}, K^{\mathrm{Xe}}$, $K^{\mathrm{Kr}}, \Delta_{\mathrm{ads}} H_{0}^{\mathrm{Xe}}, \Delta_{\mathrm{ads}} H_{0}^{\mathrm{Kr}}$ and $\Delta_{\mathrm{exc}} H_{0}$ (which is defined in Section 3 .

We display the distribution of thermodynamic properties of materials with favourable thermodynamic Xe/Kr selectivity $\left(s_{0}>1\right)$ in Figure 2 - we restrict these plots to selectivity above 1, because those are the materials of interest for separation, and doing so removes several outliers with specific geometries or binding 

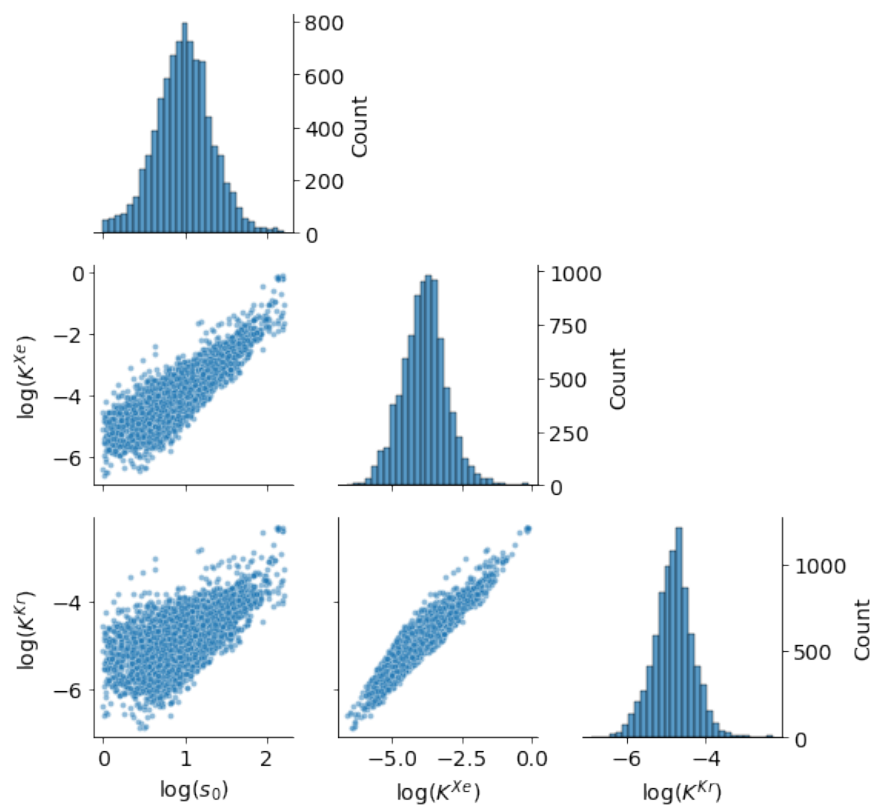

Fig. 2 For 8,401 MOFs with favourable thermodynamic Xe/Kr selectivity $\left(s_{0}>\right.$ 1 ), pair-plots of $\log _{10}\left(s_{0}\right), \log _{10}\left(K^{\mathrm{Xe}}\right)$ and $\log _{10}\left(K^{\mathrm{Kr}}\right)$ (the Henry's constants are in $\mathrm{mmol} \mathrm{g}^{-1} \mathrm{~Pa}^{-1}$ ) in the off-diagonal subplots (note that the $\mathrm{y}$-axis is displayed on the right side) and the distribution of each quantity are on the diagonal (note that the $y$-axis displayed on the right side corresponds to the count and the $\mathrm{x}$ axis is correctly labeled below each subplot).

sites (but does not change the overall conclusions). We can first see that although the logarithm of the Xe Henry's constant $K^{\mathrm{Xe}}$ is weakly correlated to the logarithm of the selectivity $s_{0}$, this correlation is stronger for highly selective materials. Therefore, in a multi-step screening study to identify the most selective materials, it could be possible to use as a "first filter" criterion based purely on Xe adsorption, discarding materials below a certain threshold (e.g., the materials with $s_{0} \geq 30$ are contained in the subset with $K^{\mathrm{Xe}} \geq 2.710^{-1} \mathrm{mmolg}^{-1} \mathrm{~Pa}^{-1}$ ). The correlation between $K^{\mathrm{Kr}}$ and $s_{0}$, on the other hand, is weaker.

With regards to Henry's constants, we see a large range of behaviour, with $K^{\mathrm{Xe}}$ ranging from $2.610^{-7} \mathrm{mmol} \mathrm{g}^{-1} \mathrm{~Pa}^{-1}$ to $7.910^{-1}$ mmolg ${ }^{-1} \mathrm{~Pa}^{-1}$, and $K^{\mathrm{Kr}}$ ranging from $1.310^{-7} \mathrm{mmolg}^{-1} \mathrm{~Pa}^{-1}$ to $5.110^{-3} \mathrm{mmolg}^{-1} \mathrm{~Pa}^{-1}$. We also see that statistically, a high affinity for xenon usually translates into a high (relative) affinity for krypton, which is a general trend for noble gases where the adsorption sites are not strongly specific. In order to look more in detail into the thermodynamics behind this large diversity in behaviour, we plot in Figure 3 the enthalpies involved.

We first observe that the low-loading adsorption enthalpy of xenon $\left(\Delta_{\mathrm{ads}} H_{0}^{\mathrm{Xe}}\right)$ is strongly correlated to that of krypton $\left(\Delta_{\mathrm{ads}} H_{0}^{\mathrm{Kr}}\right)$. Echoing the similar correlation seen between respective Henry's constants, it suggests a rather generic physisorption mechanism is at play in the majority of materials, and that hostadsorbate affinities are mainly determined by the enthalpy. The main driver of $\mathrm{Xe} / \mathrm{Kr}$ selectivity is neither the xenon or krypton adsorption enthalpy alone (both are weakly correlated to the selectivity), but as expected their difference, $\Delta_{\text {exc }} H_{0}$, which is strongly correlated to $\log \left(s_{0}\right)$. This is further confirmed by the lack
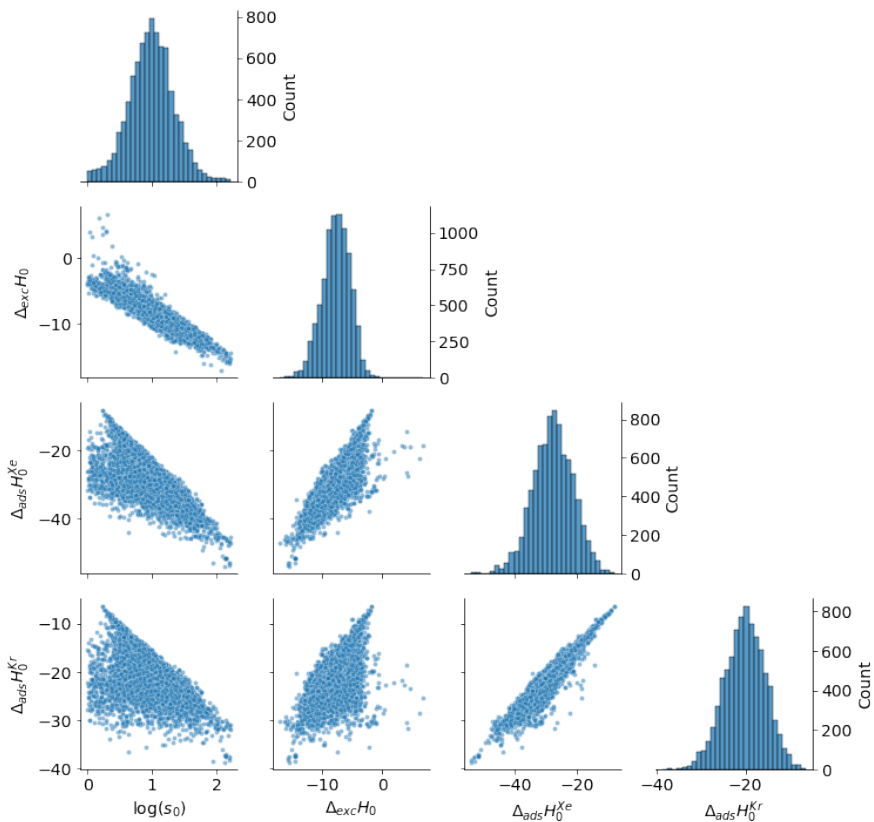

Fig. 3 For 8,401 MOFs with favourable thermodynamic $\mathrm{Xe} / \mathrm{Kr}$ selectivity $\left(s_{0}>\right.$ 1 ), pair-plots of $\log \left(s_{0}\right), \Delta_{\mathrm{exc}} H_{0}, \Delta_{\mathrm{ads}} H_{0}^{\mathrm{Xe}}$ and $\Delta_{\mathrm{ads}} H_{0}^{\mathrm{Kr}}$ (the enthalpies are in $\mathrm{kJ} \mathrm{mol}^{-1}$ ) in the off-diagonal subplots and the distribution of each quantity are on the diagonal.

of correlation between selectivity and adsorption entropies (c.f. supplementary information, Figure S2): the separation is mostly enthalpic in nature, and the entropy causes the dispersion in the correlation between selectivity $\log \left(s_{0}\right)$ and $\Delta_{\text {exc }} H_{0}$.

\subsection{The impact of pressure and its thermodynamic origins}

In this section we focus on the impact of a change of working pressure on the adsorption selectivity, and analyse its thermodynamic origins. This is key to accurately assess the thermodynamics of adsorption in different working conditions for specific industrial processes, and any insight into the impact of pressure on selectivity may allow for faster screening limited at selected thermodynamic conditions.

We calculated the selectivity $s_{1}$ at pressure 1 atm and ambient temperature using GCMC calculations on the entire dataset, with $\mathrm{Xe} / \mathrm{Kr}$ mixture composition of 20:80 (found in a byproduct stream from air separation ${ }^{83}$ ) and 90:10 (found in the off-gas streams from nuclear waste ${ }^{84}$ ). For high-selectivity materials, we find that the impact of composition appears rather marginal (c.f. supplementary information, Figure S5). In the following, we discuss the selectivity for the 20:80 mixture, which is the most commonly studied one in the literature. To measure the difference in selectivity between low and ambient pressures, we consider a relative difference $d_{r}\left(s_{0}, s_{1}\right)$ defined as follows:

$$
d_{r}\left(s_{0}, s_{1}\right)=\frac{\left|s_{0}-s_{1}\right|}{\min \left(s_{0}, s_{1}\right)}
$$

In Figure 4, the selectivity at ambient pressure $s_{1}$ is plotted against its low-pressure counterpart $s_{0}$ (for materials where $s_{0}>$ 1 , as before). The points are color-coded according to the value of 


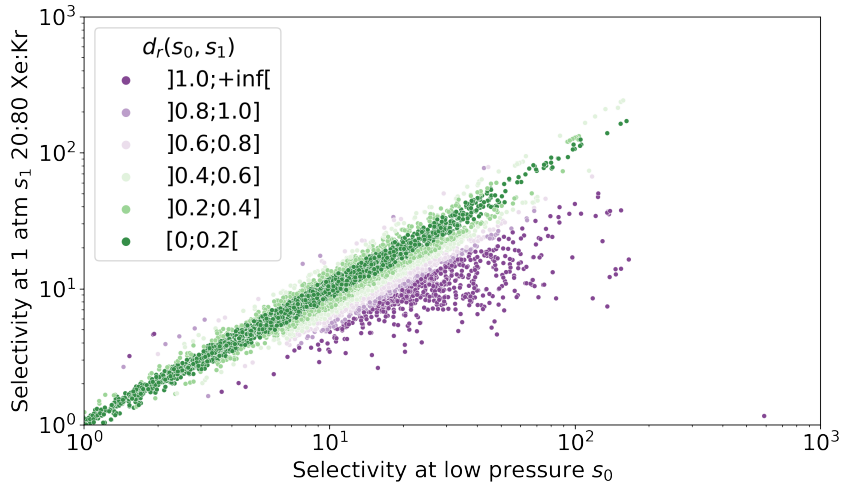

Fig. 4 Difference of selectivity between low pressure and at a $1013 \mathrm{hPa}$ pressure for a 20:80 xenon krypton composition. The relative difference between the low-pressure selectivity and the ambient-pressure is particularly high for the points labeled in purple.

$d_{r}\left(s_{0}, s_{1}\right)$, in 6 discrete categories for the sake of clarity. There is some broad level of correlation, see near the diagonal with $61.5 \%$ of materials where the difference is below 20\% (near the $s_{0}=s_{1}$ line). We also see clearly that there are many more points $(74.3 \%$ among the materials with $\left.d_{r}\left(s_{0}, s_{1}\right) \geq 0.2\right)$ below the first bisector $\left(s_{1}<s_{0}\right)$ than above: for these materials the selectivity $s_{1}$ at $1 \mathrm{~atm}$ is significantly lower than the one at low pressure $s_{0}$.

This drop in selectivity mainly concerns the materials with a relatively high selectivity $s_{0}>10$ (see Figure 4, and forewarns that considering solely pure-component Henry's constant (i.e. zeropressure selectivity) for materials screening could be misleading in some cases. Although it is simpler and faster to calculate, those low-pressure results that can overestimate selectivity by more than $100 \%$ in a significant number of materials (646 out of 9,668 in our dataset). By using a thermodynamic approach, we now try to explain the reasons behind these shifts in selectivity.

To evaluate quantitatively the thermodynamic effects at play in the competitive adsorption in different regimes, we consider thermodynamic properties of the following "exchange equilibrium":

$$
\mathrm{Xe}_{(\mathrm{g})}+\mathrm{Kr}_{(\mathrm{ads})} \rightleftharpoons \mathrm{Xe}_{(\mathrm{ads})}+\mathrm{Kr}_{(\mathrm{g})}
$$

as described in Section 3.4. We plot in Figure 5 the exchange entropy at low pressure (plotted as $T \Delta_{\text {exc }} S_{0}$ ) against the exchange enthalpy $\Delta_{\text {exc }} H_{0}$. In this scatter plot, the points are color-coded according to the selectivity $s_{0}$ (with discrete categories for the sake of clarity), which is related to the enthalpy and entropy through Equation 3 - meaning iso-selectivity lines are parallel straight lines in this scatter plot.

In the supplementary information Figure S8, we display the distributions of the exchange enthalpy and entropy at low pressure. For the 630 most selective materials $\left(s_{0}>30\right)$, the distribution of the exchange enthalpy $\Delta_{\text {exc }} H_{0}$ is centered on $-12.0 \mathrm{~kJ} \mathrm{~mol}^{-1}$ with a standard deviation of $1.3 \mathrm{~kJ} \mathrm{~mol}^{-1}$, whereas the distribution of the exchange entropy (plotted as $T \Delta_{\text {exc }} S_{0}$ ) is centered on $-2.5 \mathrm{~kJ} \mathrm{~mol}^{-1}$ with a standard deviation of $0.7 \mathrm{~kJ} \mathrm{~mol}^{-1}$. These figures, along with the overall distribution plotted in Figure 5, further confirms the moderate role of entropy in the low-pressure se-

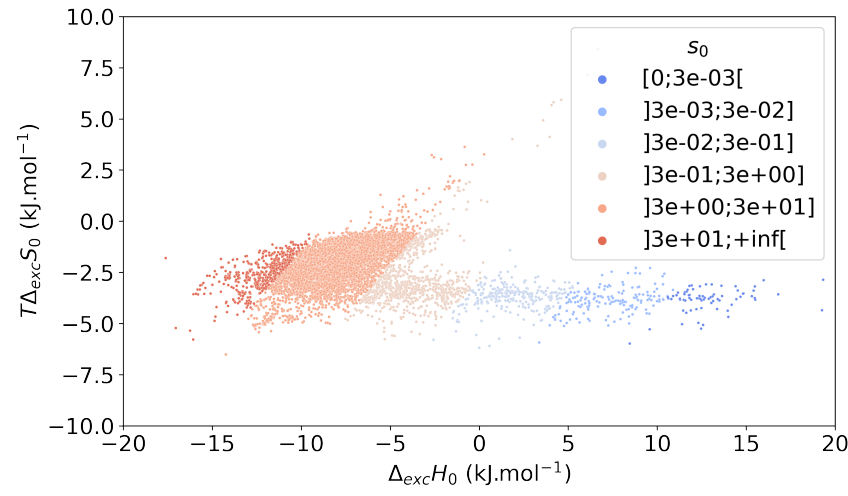

Fig. 5 The energetic equivalent of exchange entropy $T \Delta_{\mathrm{exc}} S_{0}$ and enthalpy $\Delta_{\text {exc }} H_{0}$ at low pressure labeled using the selectivity $s_{0}$ at low pressure. The limits between labels follows a affine function of slope $1 / T$ and of intercept $-R \ln \left(s_{0}^{\lim }\right)$ where $s_{0}^{\lim }$ is the limit selectivity value (cf. Equation 3). In other words, the iso-selectivity lines are all parallel lines of equation $y=f(x)$ where $f$ is the affine function described previously.

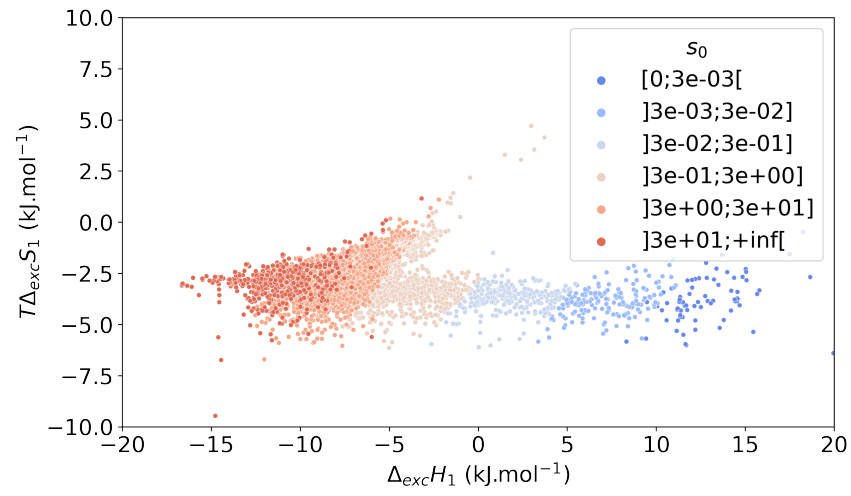

Fig. 6 The energetic equivalent of exchange entropy $T \Delta_{\text {exc }} S_{1}$ and enthalpy $\Delta_{\text {exc }} H_{1}$ at ambient pressure labeled using the selectivity $s_{0}$ at low pressure. The points are layered so that the points with higher $s_{0}$ are always above. To see a split version of this plot, please refer to the Figure S6 in the supplementary information.

lectivity: it is equivalent in average to about $20 \%$ of the exchange enthalpy at low pressure.

Figure 6 represents a scatter plot of the exchange entropy at $P=1 \mathrm{~atm} \Delta_{\mathrm{exc}} S_{1}$ against the exchange enthalpy at ambient pressure $\Delta_{\text {exc }} H_{1}$. To compare it to the Fig. 5, the points are color-coded according to the low-pressure selectivity $s_{0}$. Compared to the isoselectivity $s_{1}$ straight parallel lines (c.f. supplementary information Figure S7), we can see that many materials with high $s_{0}$ have lower $s_{1}$ - seen as a migration of points to the right of the plot, compared to Fig. 5. This shift is therefore mainly due to a higher (less favourable) exchange enthalpy, hinting at an important role of enthalpy to determine higher pressure selectivity.

To quantify this change, we consider the distributions of the exchange enthalpy $\Delta_{\text {exc }} H_{1}$ and the energetic equivalent of the exchange entropy $T \Delta_{\text {exc }} S_{1}$ at ambient pressure (Figures S9). The enthalpy $\Delta_{\text {exc }} H_{1}$ is now centred on $-11.1 \mathrm{~kJ} \mathrm{~mol}^{-1}$ with a standard deviation of $1.9 \mathrm{~kJ} \mathrm{~mol}^{-1}$. Compared to the zero-pressure values, the enthalpy distribution is more dispersed, showing that there 
are important changes in individual values, and is higher in average - majority of materials have lower ambient pressure selectivity due to enthalpic effects. This can be explained by the very general increase of adsorption enthalpy upon loading in the gas phase, which is linked to the presence of more adsorbed molecules. In fact, the correlations (Figure 2) suggest that highly selective materials have high affinity in xenon, therefore they feature significant uptake at $1 \mathrm{~atm}$ and the large Xe loading means the most favourable adsorption sites can be saturated, and further adsorption involves weaker host-guest interactions and therefore increases the average adsorption enthalpy at nonzero loading.

The entropic term $T \Delta_{\text {exc }} S_{1}$ is now centred on $-2.9 \mathrm{~kJ} \mathrm{~mol}^{-1}$, with a standard deviation of $0.8 \mathrm{~kJ} \mathrm{~mol}^{-1}$ (almost unchanged from low-pressure). The entropy is on average lower, which means an overall less favourable separation due to entropic effects: this evolution of the entropic term hints at the potential of reorganisation of the adsorbed molecules inside each material. The difference in distribution of enthalpy has, overall, more impact on the highpressure selectivity than that of entropy. This suggests that the overall contribution of enthalpy remains more decisive than the role of entropy in the selectivity change, even at ambient pressure. This is an interesting conclusion for screening studies, because evaluation of adsorption enthalpy can be computationally faster than that of the adsorption free energy (or entropy).

\subsection{Enthalpic and entropic contributions to the change in selectivity}

To further investigate the thermodynamics of the selectivity change, we quantify in this section the contributions of enthalpy and entropy. The ratio $s_{1} / s_{0}$ is equal to the product $k_{\mathrm{H}} \times k_{\mathrm{S}}$ where $k_{\mathrm{H}}$ and $k_{\mathrm{S}}$ are the enthalpic and entropic contributions to the selectivity change defined as:

$$
\begin{aligned}
& k_{\mathrm{H}}=\exp \left(-\frac{\Delta_{\mathrm{exc}} H_{1}-\Delta_{\mathrm{exc}} H_{0}}{R T}\right) \\
& k_{\mathrm{S}}=\exp \left(\frac{\Delta_{\mathrm{exc}} S_{1}-\Delta_{\mathrm{exc}} S_{0}}{R}\right)
\end{aligned}
$$

As we can see in Figure 7, the entropic contribution $k_{\mathrm{S}}$ has a belllike distribution, with a mean of 0.9 and a standard deviation of 0.6 . This confirms that $k_{\mathrm{S}}$ is close to 1 , and has therefore only a marginal effect on the selectivity change. On the other hand the enthalpic contribution $k_{\mathrm{H}}$ has a more uniform distribution ranging from 0.1 to 1.5 , which means that enthalpy has a crucial role in the selectivity change we observe. There are a significant number of materials with a $k_{\mathrm{H}}$ close to zero, they correspond to the same materials highlighted in Section 4.2 .

Furthermore, the scatter plot of $k_{\mathrm{H}}$ and $k_{\mathrm{S}}$ (shown in Figure 8 ) confirms a rather moderate effect of entropy. For most of the materials with $0.25 \leq k_{\mathrm{H}} \leq 1.75$, we see that $k_{\mathrm{S}}$ is close to 1 . The most significant entropic contributions are found for materials where $k_{\mathrm{H}}$ is close to zero (typically below 0.25 ). If we look in more detail at the 29 materials with $k_{\mathrm{S}}>2$, the entropic contribution $k_{\mathrm{S}}$ moderately compensate the enthalpic contribution as the average ratio $s_{1} / s_{0}$ is around 0.25 . In such cases, the entropy is non negligible and it can partially compensate the enthalpic contribution
Table 1 Enthalpic and entropic contributions on the selectivity change for some archetypal structures selected for their high $s_{0}$ selectivity. Every structure is identified using a CSD Refcode and the first article that mentions it

\begin{tabular}{lrrrrrr}
\hline CSD Refcode & Ref. & $s_{0}$ & $s_{1}$ & $s_{1} / s_{0}$ & $k_{\mathrm{H}}$ & $k_{\mathrm{S}}$ \\
\hline VOKJIQ & $\mathbf{8 5}$ & 157.17 & 242.73 & 1.54 & 1.46 & 1.06 \\
KAXQIL & $\mathbf{8 6}$ & 103.78 & 132.57 & 1.28 & 1.32 & 0.96 \\
JUFBIX & $\mathbf{8 7}$ & 106.11 & 114.83 & 1.08 & 1.08 & 1.00 \\
FALQOA & $\mathbf{8 8}$ & 162.20 & 171.10 & 1.05 & 1.09 & 0.96 \\
GOMREG & $\overline{89}$ & 114.14 & 73.83 & 0.65 & 1.01 & 0.64 \\
JAVTAC & $\overline{90}$ & 117.38 & 66.93 & 0.57 & 0.77 & 0.74 \\
GOMRAC & $\overline{89}$ & 124.11 & 47.34 & 0.38 & 0.58 & 0.66 \\
MISQIQ & $\overline{91}$ & 138.94 & 37.32 & 0.27 & 0.51 & 0.53 \\
BAEDTA01 & $\mathbf{9 2}$ & 154.10 & 37.74 & 0.24 & 0.12 & 1.97 \\
VIWMOF & $\mathbf{9 3}$ & 81.13 & 13.24 & 0.16 & 0.04 & 4.30 \\
LUDLAZ & $\mathbf{9 4}$ & 165.68 & 16.42 & 0.10 & 0.16 & 0.63 \\
WOJJOV & $\mathbf{9 5}$ & 146.32 & 13.94 & 0.10 & 0.06 & 1.68 \\
VAPBIZ & 96 & 146.73 & 12.76 & 0.09 & 0.06 & 1.50 \\
\hline
\end{tabular}

to the selectivity change, but the general trend is still given by enthalpy, since the overall selectivity is decreasing as a result.

\subsection{Detailed investigation of some archetypal thermody- namic behaviours}

In this section, we go over some of the most selective materials, as identified at low pressure and listed in Table 1 , and we provide a detailed investigation of the thermodynamic effects behind their behaviour. We can split them into three main categories: materials with a slight increase in selectivity or little change in selectivity $\left(s_{0} / s_{1}>0.8\right)$, materials with a slight decrease in selectivity $(0.5 \leq$ $\left.s_{0} / s_{1} \leq 0.8\right)$ and materials with a significant decrease in selectivity $\left(s_{0} / s_{1}<0.5\right)$. In this section, we investigate the origins of these different behaviours: all materials are referenced by their CSD refcode.

We first study a few examples of the category of materials where ambient-pressure selectivity is close to (or even higher than) the low-pressure value. For VOKJIQ, the selectivity is multiplied by 1.5 between low and ambient pressure. We see that the adsorption enthalpy of xenon $\Delta_{\mathrm{ads}} H^{\mathrm{Xe}}$ decreases from $-53.9 \mathrm{~kJ} \mathrm{~mol}^{-1}$ to $-61.1 \mathrm{~kJ} \mathrm{~mol}^{-1}$, whereas for krypton $\Delta_{\mathrm{ads}} H^{\mathrm{Kr}}$ decreases from $-38.2 \mathrm{~kJ} \mathrm{~mol}^{-1}$ to $-44.5 \mathrm{~kJ} \mathrm{~mol}^{-1}$ (c.f. supplementary information Table S1). This increased stability of the adsorption sites upon loading is not common in nanoporous materials for rare gas adsorption, and can be linked to a cooperative effect between the adsorbed molecules. The stabilisation favours the xenon molecules over the krypton molecules, due to an interatomic distance inside the pores that is a closer match to the energy well for favourable Lennard-Jones potential for xenon-xenon interactions than for krypton-krypton interactions (which is the case for a distance higher than $4.2 \AA$; see Figure S10).

In the case of KAXQIL, the channels are one-dimensional tubes (see Figure S12) and the distance between two adsorption sites is approximately the unit cell parameter along the direction of the tube (5.6 ). There the selectivity increases with pore filling, for enthalpic reasons, which we can explain by relatively simple reasoning. The Lennard-Jones potentials $V_{\mathrm{LJ}}$ can be estimated for all species at $5.6 \AA$ : $V_{\mathrm{Xe}-\mathrm{Xe}}=-1.0 \mathrm{~kJ} \mathrm{~mol}^{-1}, V_{\mathrm{Kr}-\mathrm{Kr}}=-0.3 \mathrm{~kJ} \mathrm{~mol}^{-1}$ and $V_{\mathrm{Xe}-\mathrm{Kr}}=-0.5 \mathrm{~kJ} \mathrm{~mol}^{-1}$. In a simplistic model where all ad- 

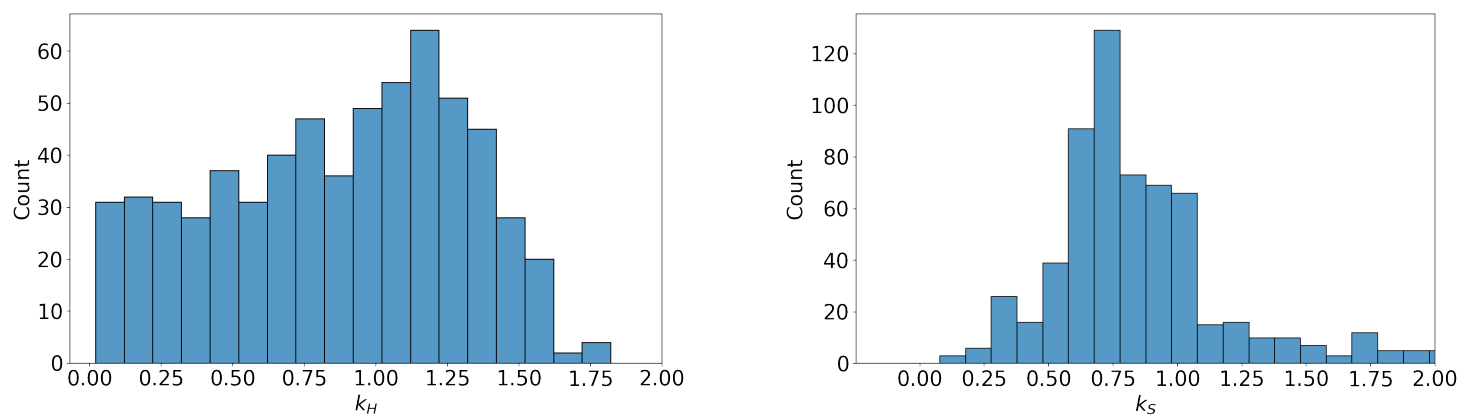

Fig. 7 Distribution of the enthalpic $k_{\mathrm{H}}$ and entropic $k_{\mathrm{S}}$ contributions to the change of selectivity from low to ambient pressure for the 630 materials with $s_{0}>30 . k_{\mathrm{H}}$ has a rather uniform distribution, whereas $k_{\mathrm{S}}$ has a bell-like distribution.

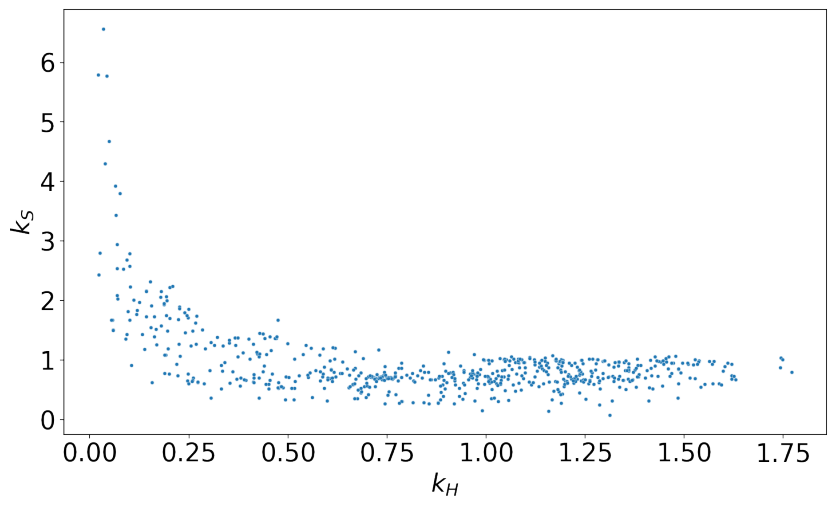

Fig. 8 Scatter plot of the enthalpic contribution $k_{\mathrm{H}}$ and entropic contribution $k_{S}$ for the 630 materials with $s_{0}>30$. The entropic compensation occurs when the enthalpic contribution is around 0.1 , else its value is around 1 and has little effect on the selectivity change.

sorbed molecules are $5.6 \AA$ apart, the cooperative effect is higher between two xenon molecules, which explains the increased selectivity at high uptake. If we look further at the adsorption enthalpy of both xenon and krypton (c.f. supplementary information Table S1), they both increase: the guest molecules move from the "ideal" adsorption sites, and the guest-guest interactions do not fully compensate. The selectivity change in this material is therefore a consequence of the guest-guest interactions that rearranges the position of the adsorbates inside the nanopores.

To further corroborate the role of the guest-guest interactions, we look at another material with one-dimensional tube-like channels: JUFBIX, a cobalt(II) coordination polymer based on carboxylic acid linkers (see Figure S13). 87 The periodicity along the direction of the tubes is much higher at $7.2 \AA$. The pair interaction energies corresponding to the LJ potentials at this distance are $V_{\mathrm{Xe}-\mathrm{Xe}}=-0.24 \mathrm{~kJ} \mathrm{~mol}^{-1}, V_{\mathrm{Kr}-\mathrm{Kr}}=-0.06 \mathrm{~kJ} \mathrm{~mol}^{-1}$ and $V_{\mathrm{Xe}-\mathrm{Kr}}=-0.13 \mathrm{~kJ} \mathrm{~mol}^{-1}$. By looking at the adsorption enthalpies (Table 1), these values are too small to affect the position of the adsorbed molecules. At high loading, the distance between adsorbed molecules is high and every adsorption site is independent from the others. The ambient-pressure selectivity $s_{1}$ is therefore the same as the low-pressure selectivity $s_{0}$, since every guestguest interactions are negligible. It confirms the crucial role of cooperative effects between guest molecules, when considering a saturated material.
GOMREG and JAVTAC are frameworks that belong to the second category of materials, with a moderate decrease in selectivity from low to ambient pressure. In GOMREG, the channels are composed of one-dimensional tubes larger than the ones found in KAXQIL or JUFBIX (see Figure S15 and Table S1). The adsorption sites are alternating from left to right inside the channel, and the adsorbed molecules organise in a "zigzag" pattern. Looking at the adsorption enthalpies, we see that both xenon and krypton have lower enthalpies by a similar margin, suggesting an equivalent stabilisation for both atoms, hence the enthalpic contribution to the selectivity change is close to 1 . Since krypton is smaller and less strongly tied on its adsorption site than xenon, it has more available space inside the pore space. This gives an entropic advantage to the $\mathrm{Kr}$, seen in the entropic contribution $k_{\mathrm{S}}$ of 0.64 in Table 1 . This indicates that even if enthalpic considerations mainly explain the observed changes at a statistical level, as discussed in the previous sections, for individual cases entropic considerations can be a strong factor in pressure-dependent selectivity.

The remaining materials discussed here form a third category, with a strong decrease in selectivity from low to ambient pressure. We look at several phenomena that can be at the root of this decrease, which is important for screening studies as it can limit the working performance of a material that appears to be a "top performer" based on zero-pressure screening.

For example, GOMRAC has a similar structure compared to GOMREG (see Figure S17), except for the fact that the pores and channels are smaller (see the values of $D_{f}$ the diameter of the largest free sphere, and $D_{i}$ the diameter of the largest included sphere, in Table S1). The distances between the adsorbed molecules - in their ideal sites - are then consequently smaller. At such distances, we can assume that the interactions between adsorbates become more stabilising for krypton than for xenon molecules in GOMRAC (see LJ potentials at distance lower than $4.2 \AA$ in the Figure S10), which translates into an enthalpic contribution $k_{\mathrm{H}}$ of 0.58 . Moreover, this is compatible with the equivalent guest-guest interactions in GOMREG, as previously discussed. It explains why difference between the adsorption enthalpies become smaller for GOMRAC, whereas it stays the same for GOMREG (between low and ambient pressure). This further validates the crucial role of the interactions between adsorbed molecules, and their relationship with the guest-guest distances when con- 

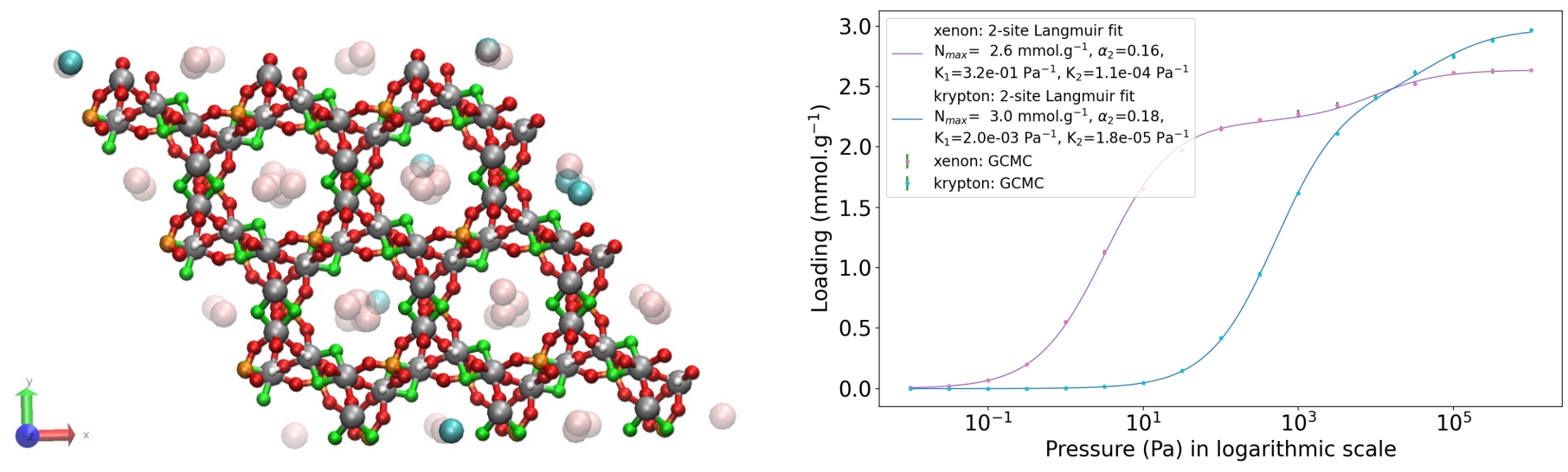

Fig. 9 Representation of a chiral open-framework fluoroaluminophosphate $\left[\mathrm{C}_{4} \mathrm{~N}_{3} \mathrm{H}_{16}\right] \cdot\left[\mathrm{Al}_{6} \mathrm{P}_{3} \mathrm{O}_{12} \mathrm{~F}_{6}(\mathrm{OH})_{6}\right]$ denoted AIPO-JU89 (referenced MISQIQ in the Cambridge structural database), which has been loaded with xenon and krypton in a GCMC simulation, on the left side. ${ }^{91}$ Color code: $\mathrm{Al}$ in silver, $\mathrm{P}$ in orange, $\mathrm{O}$ in red, $\mathrm{H}$ in white and $\mathrm{F}$ in green for the framework; and $\mathrm{Xe}$ in transparent pink and $\mathrm{Kr}$ in cyan for the adsorbates. The pure-component isotherms fitted with a 1-site Langmuir model for both xenon and krypton at $298 \mathrm{~K}$ on the right side (for more information on the Langmuir parameters see supplementary information Equation (S5)).

sidering a high loading condition.

If we look at the case of MISQIQ, we see that the purecomponent Xe isotherm in Figure 9 cannot be fitted by a singlesite Langmuir isotherm, but is well fitted by a two-site Langmuir model (see Figure S18). Visual inspection of the adsorbed density at various loadings shows that this is not a second, separate adsorption site that is populated at high loading: instead, the second step in the isotherm (representing about $20 \%$ of the uptake at full loading) is associated with a reorganisation of the adsorbate molecules occurs at high loading, accompanying a contraction of the interatomic distances. In this case, the potential for reorganisation of the adsorbate in the material's nanopores leads to the change in selectivity. This reorganisation can be detected on the basis of the xenon isotherm alone, and has a major role in the selectivity at ambient pressure. This repacking of the adsorbed phase is linked to a strong entropic effect, and also impacts the enthalpic contribution to selectivity.

More extreme cases of selectivity drop can occur when more than one site is available, as is the case for materials BAEDTA01, VIWMOF, LUDLAZ, WOJJOV, and VAPBIZ. The pure-component isotherms and the representation of the materials loaded in xenon and krypton molecules (presented in supporting information Figures S19-23) confirm the existence of at least two distinct adsorption sites in each material. The most selective sites (i.e., the most favourable for $\mathrm{Xe}$ ) are filled in priority at low loading, and the less selective sites will then be populated when the pressure increases, leading to a net selectivity drop at ambient pressure for these materials. The different types of adsorption sites, and therefore the potential for a drop in $\mathrm{Xe} / \mathrm{Kr}$ selectivity (at non-zero pressure) is a factor that could be explicitly included in screening of pure-component isotherms, without the need for explicit multicomponent GCMC simulations.

\section{Conclusions and perspectives}

In the current state of the art on $\mathrm{Xe} / \mathrm{Kr}$ separation by adsorption in nanoporous materials, many studies have focused on the determination of structure/property relationships, the description of theoretical limits of performance, and the identification of top- performing materials, whether for existing experimental structures or for novel hypothetical structures yet to be synthesised. Here, we provide a study based on a high-throughput screening of the adsorption of $\mathrm{Xe}, \mathrm{Kr}$, and $\mathrm{Xe} / \mathrm{Kr}$ mixtures in 12,020 experimental open-framework materials, in order to provide a better comprehension of the thermodynamics behind $\mathrm{Xe} / \mathrm{Kr}$ separation in nanoporous materials and the microscopic origins of $\mathrm{Xe} / \mathrm{Kr}$ selectivity at both low and ambient pressure.

The statistical correlation found between Henry's constant for $\mathrm{Xe}$ and $\mathrm{Xe} / \mathrm{Kr}$ selectivity showed that the most selective materials are those with the highest affinity for xenon. To some degree of accuracy, we conclude that directly screening for $\mathrm{Kr}$ adsorption or for Xe free energy may not be necessary for a coarsegrained evaluation of a nanoporous framework selectivity. This could help building more efficient screening methodologies, for example with multi-step studies with a first rough selection on Henry's constant at a low computational cost, followed by more expensive GCMC simulations on the selected materials (a gain that can be between 5 and 10-fold in our setup). Furthermore, inspection of the correlations between enthalpy and entropy contributions at low pressure showed that the adsorption-based separation process in the open-frameworks studied is mainly enthalpic in nature. We intend to extend the study in the future to other classes of nanoporous materials beyond MOFs, including covalent organic frameworks, porous aromatic frameworks, purely inorganic porous frameworks such as zeolites, but also amorphous porous materials such as porous polymer membranes.

In order to use nanoporous materials to separate xenon from krypton, pressure swing adsorption (PSA) processes have been widely proposed: pressure is therefore a crucial thermodynamic variable in the separation cycle. Here, we studied the difference of selectivity between a system under very low pressure (at the zero loading limit, which is calculated at relatively low computational cost) and a system at ambient pressure (closer to working conditions, but obtained at higher simulation cost). We demonstrated that the selectivity could be highly dependent on the pressure, with high low-pressure selectivity that could be maintained in some materials at ambient-pressure selectivity, while in others 
there would be a large drop in selectivity: a high ambient-pressure selectivity requires high low-pressure selectivity, but the reverse does not hold.

Using a thermodynamic approach to describe the separation selectivity, we showed that the differences in selectivity between the different pressures (and therefore different loading regimes of the frameworks) are mainly explained by the evolution of the adsorption enthalpies for Xe and Kr. By focusing on specific examples, we uncovered the microscopic origins of these selectivity changes, and related them to the relative roles of host-guest and guest-guest interactions. Population of different adsorption sites, or repacking of the adsorbed phase at higher loading, can lead to drastic changes in the overall selectivity. The mechanisms behind selectivity at high pressure are complex and unique to each framework, requiring a good understanding of the interactions between guest molecules constrained in the nanopores. Nevertheless, our classification of the interactions at play can help in the future to design more efficient high-throughput screening procedures.

\section{Conflicts of interest}

There are no conflicts of interest to declare

\section{Acknowledgements}

The authors acknowledge financial support from Orano. We thank Philippe Guilbaud and Isabelle Hablot for discussions on the topic of adsorption-based Xe/Kr separation. This work was supported by the Agence Nationale de la Recherche (project MATAREB, ANR-18-CE29-0009-01), and access to HPC platforms was provided by a GENCI grant (A0090807069).

\section{Notes and references}

1 G. Hautier, Comput. Mater. Sci., 2019, 163, 108-116.

2 J. M. Cole, Acc. Chem. Res., 2020, 53, 599-610.

3 A. Ludwig, npj Comput. Mater., 2019, 5, 0121.

4 H. S. Stein and J. M. Gregoire, Chem. Sci., 2019, 10, 96409649.

5 C. E. Wilmer, M. Leaf, C. Y. Lee, O. K. Farha, B. G. Hauser, J. T. Hupp and R. Q. Snurr, Nature Chem., 2012, 4, 83-89.

6 P. G. Boyd and T. K. Woo, CrystEngComm, 2016, 18, 37773792.

7 D. A. Gómez-Gualdrón, C. E. Wilmer, O. K. Farha, J. T. Hupp and R. Q. Snurr, J. Phys. Chem. C, 2014, 118, 6941-6951.

8 M. Moliner, Y. Román-Leshkov and A. Corma, Acc. Chem. Res., 2019, 52, 2971-2980.

9 J. L. Salcedo Perez, M. Haranczyk and N. E. R. Zimmermann, Z. Kristallogr., 2019, 234, 437-450.

10 Nature New Biology, 1971, 233, 223-223.

11 S. Gražulis, D. Chateigner, R. T. Downs, A. F. T. Yokochi, M. Quirós, L. Lutterotti, E. Manakova, J. Butkus, P. Moeck and A. Le Bail, J. Appl. Crystallogr., 2009, 42, 726-729.

12 C. R. Groom, I. J. Bruno, M. P. Lightfoot and S. C. Ward, Acta Crystallogr. B, 2016, 72, 171-179.

13 F.-X. Coudert, Adv. Theory Simul., 2019, 2, 1900131.
14 J. J. de Pablo, B. Jones, C. L. Kovacs, V. Ozolins and A. P. Ramirez, Curr. Op. Solid State Mater. Sci., 2014, 18, 99-117.

15 J. J. de Pablo, N. E. Jackson, M. A. Webb, L.-Q. Chen, J. E. Moore, D. Morgan, R. Jacobs, T. Pollock, D. G. Schlom, E. S. Toberer, J. Analytis, I. Dabo, D. M. DeLongchamp, G. A. Fiete, G. M. Grason, G. Hautier, Y. Mo, K. Rajan, E. J. Reed, E. Rodriguez, V. Stevanovic, J. Suntivich, K. Thornton and J.C. Zhao, npj Comput. Mater., 2019, 5, 99.

16 A. Jain, S. P. Ong, G. Hautier, W. Chen, W. D. Richards, S. Dacek, S. Cholia, D. Gunter, D. Skinner, G. Ceder and K. A. Persson, APL Mater., 2013, 1, 011002.

17 A. Jain, K. A. Persson and G. Ceder, APL Mater., 2016, 4, 053102.

18 M. D. Foster, O. Delgado Friedrichs, R. G. Bell, F. A. Almeida Paz and J. Klinowski, J. Am. Chem. Soc., 2004, 126, 9769-9775.

19 C. E. Wilmer and R. Q. Snurr, Topics in Current Chemistry, Springer International Publishing, 2013, pp. 257-289.

20 V. Tshitoyan, J. Dagdelen, L. Weston, A. Dunn, Z. Rong, O. Kononova, K. A. Persson, G. Ceder and A. Jain, Nature, 2019, 571, 95-98.

21 C. J. Court and J. M. Cole, npj Comput. Mater, 2020, 6, 38.

22 K. T. Butler, D. W. Davies, H. Cartwright, O. Isayev and A. Walsh, Nature, 2018, 559, 547-555.

23 E. Kim, K. Huang, S. Jegelka and E. Olivetti, npj Comput. Mater., 2017, 3, 1120.

24 G. Borboudakis, T. Stergiannakos, M. Frysali, E. Klontzas, I. Tsamardinos and G. E. Froudakis, npj Comput. Mater., 2017, 3, 1-7.

25 S. Chibani and F.-X. Coudert, APL Mater., 2020, 8, 080701.

26 S. Chibani and F.-X. Coudert, Chem. Sci., 2019, 10, 85898599.

27 R. Gaillac, S. Chibani and F.-X. Coudert, Chem. Mater, 2020, 32, 2653-2663.

28 C. Toher, J. J. Plata, O. Levy, M. de Jong, M. Asta, M. B. Nardelli and S. Curtarolo, Phys. Rev. B, 2014, 90, 174107.

29 S. Sarikurt, T. Kocabaş and C. Sevik, J. Mater. Chem. A, 2020, 8, 19674-19683.

30 J. Hachmann, R. Olivares-Amaya, S. Atahan-Evrenk, C. Amador-Bedolla, R. S. Sánchez-Carrera, A. Gold-Parker, L. Vogt, A. M. Brockway and A. Aspuru-Guzik, J. Phys. Chem. Lett., 2011, 2, 2241-2251.

31 D. W. Davies, K. T. Butler, A. J. Jackson, A. Morris, J. M. Frost, J. M. Skelton and A. Walsh, Chem, 2016, 1, 617-627.

32 X. Zhang, A. Chen and Z. Zhou, WIREs Comput. Mol. Sci., 2019, 9, e1385.

33 A. K. Singh, K. Mathew, H. L. Zhuang and R. G. Hennig, J. Phys. Chem. Lett., 2015, 6, 1087-1098.

34 J. Greeley, T. F. Jaramillo, J. Bonde, I. Chorkendorff and J. K. Nørskov, Nature Mater., 2006, 5, 909-913.

35 S. Back, K. Tran and Z. W. Ulissi, ACS Appl. Mater. Interfaces, 2020, 12, 38256-38265.

36 T. Watanabe and D. S. Sholl, Langmuir, 2012, 28, 14114 14128. 
37 J. Kim, L.-C. Lin, R. L. Martin, J. A. Swisher, M. Haranczyk and B. Smit, Langmuir, 2012, 28, 11914-11919.

38 S. Han, Y. Huang, T. Watanabe, Y. Dai, K. S. Walton, S. Nair, D. S. Sholl and J. C. Meredith, ACS Comb. Sci., 2012, 14, 263267.

39 J. D. Evans, G. Fraux, R. Gaillac, D. Kohen, F. Trousselet, J.-M. Vanson and F.-X. Coudert, Chem. Mater., 2016, 29, 199-212.

40 P. Pullumbi, F. Brandani and S. Brandani, Curr. Op. Chem. Eng., 2019, 24, 131-142.

41 D. Banerjee, C. M. Simon, S. K. Elsaidi, M. Haranczyk and P. K. Thallapally, Chem, 2018, 4, 466-494.

42 S. C. Cullen and E. G. Gross, Science, 1951, 113, 580-582.

43 T. F. Holsträter, M. Georgieff, K. J. Föhr, W. Klingler, M. E. Uhl, T. Walker, S. Köster, G. Grön and O. Adolph, The Journal of the American Society of Anesthesiologists, 2011, 115, 398-407.

44 B. J. Sikora, C. E. Wilmer, M. L. Greenfield and R. Q. Snurr, Chem. Sci., 2012, 3, 2217.

45 D. Banerjee, A. J. Cairns, J. Liu, R. K. Motkuri, S. K. Nune, C. A. Fernandez, R. Krishna, D. M. Strachan and P. K. Thallapally, Acc. Chem. Res., 2015, 48, 211-219.

46 T. Zhou, Z. Song and K. Sundmacher, Engineering, 2019, 5, 1017-1026.

47 P. G. Boyd, Y. Lee and B. Smit, Nature Rev. Mater., 2017, 2, 1.

48 K. Adil, Y. Belmabkhout, R. S. Pillai, A. Cadiau, P. M. Bhatt, A. H. Assen, G. Maurin and M. Eddaoudi, Chem. Soc. Rev., 2017, 46, 3402-3430.

49 A. Sturluson, M. T. Huynh, A. R. Kaija, C. Laird, S. Yoon, F. Hou, Z. Feng, C. E. Wilmer, Y. J. Colón, Y. G. Chung, D. W. Siderius and C. M. Simon, Mol. Simulat., 2019, 45, 10821121.

50 H. Daglar and S. Keskin, Coord. Chem. Rev., 2020, 422, 213470.

51 A. Monpezat, S. Topin, L. Deliere, D. Farrusseng and B. Coasne, Ind. Eng. Chem. Res., 2019, 58, 4560-4571.

52 C. M. Simon, R. Mercado, S. K. Schnell, B. Smit and M. Haranczyk, Chem. Mater., 2015, 27, 4459-4475.

53 J. Liu, P. K. Thallapally and D. Strachan, Langmuir, 2012, 28, 11584-11589.

54 J. Liu, C. A. Fernandez, P. F. Martin, P. K. Thallapally and D. M. Strachan, Ind. Eng. Chem. Res., 2014, 53, 12893-12899.

55 Y.-S. Bae, B. G. Hauser, Y. J. Colón, J. T. Hupp, O. K. Farha and R. Q. Snurr, Micropor. Mesopor. Mater., 2013, 169, 176-179.

56 M. V. Parkes, C. L. Staiger, J. J. Perry IV, M. D. Allendorf and J. A. Greathouse, Phys. Chem. Chem. Phys., 2013, 15, 9093.

57 L. Chen, P. S. Reiss, S. Y. Chong, D. Holden, K. E. Jelfs, T. Hasell, M. A. Little, A. Kewley, M. E. Briggs, A. Stephenson, K. M. Thomas, J. A. Armstrong, J. Bell, J. Busto, R. Noel, J. Liu, D. M. Strachan, P. K. Thallapally and A. I. Cooper, Nature Mater., 2014, 13, 954-960.

58 S. Xiong, Q. Liu, Q. Wang, W. Li, Y. Tang, X. Wang, S. Hu and B. Chen, J. Mater. Chem. A, 2015, 3, 10747-10752.

59 S.-J. Lee, T.-U. Yoon, A.-R. Kim, S.-Y. Kim, K.-H. Cho, Y. K. Hwang, J.-W. Yeon and Y.-S. Bae, J. Hazard. Mater., 2016, 320, 513-520.
60 S.-J. Lee, S. Kim, E.-J. Kim, M. Kim and Y.-S. Bae, Chem. Eng. J., 2018, 335, 345-351.

61 Q. Wang, H. Wang, S. Peng, X. Peng and D. Cao, J. Phys. Chem. C, 2014, 118, 10221-10229.

62 R. Anderson, B. Schweitzer, T. Wu, M. A. Carreon and D. A. Gómez-Gualdrón, ACS Appl. Mater. Interfaces, 2017, 10, 582592.

63 M. Tong, Y. Lan, Q. Yang and C. Zhong, Chem. Eng. Sci., 2017, 168, 456-464.

64 T. Vazhappilly, T. K. Ghanty and B. N. Jagatap, J. Phys. Chem. C, 2016, 120, 10968-10974.

65 P. Zarabadi-Poor and R. Marek, ACS Sustainable Chem. Eng., 2018, 6, 15001-15006.

66 Y. Tao, Y. Fan, Z. Xu, X. Feng, R. Krishna and F. Luo, Inorg. Chem., 2020, 59, 11793-11800.

67 K. B. Idrees, Z. Chen, X. Zhang, M. R. Mian, R. J. Drout, T. Islamoglu and O. K. Farha, Chem. Mater., 2020, 32, 3776-3782.

68 P. Zhang, Y. Zhong, Q. Yao, X. Liu, Y. Zhang, J. Wang, Q. Deng, Z. Zeng and S. Deng, J. Chem. Eng. Data, 2020, 65, 40184023.

69 L. Li, L. Guo, Z. Zhang, Q. Yang, Y. Yang, Z. Bao, Q. Ren and J. Li, J. Am. Chem. Soc., 2019, 141, 9358-9364.

70 X.-l. Xiong, G.-h. Chen, S.-t. Xiao, Y.-g. Ouyang, H.-b. Li and Q. Wang, J. Phys. Chem. C, 2020, 124, 14603-14612.

71 Y. J. Colón and R. Q. Snurr, Chem. Soc. Rev., 2014, 43, 57355749.

72 O. K. Farha, I. Eryazici, N. C. Jeong, B. G. Hauser, C. E. Wilmer, A. A. Sarjeant, R. Q. Snurr, S. T. Nguyen, A. O. Yazaydın and J. T. Hupp, J. Am. Chem. Soc., 2012, 134, 15016-15021.

73 C. M. Simon, J. Kim, D. A. Gomez-Gualdron, J. S. Camp, Y. G. Chung, R. L. Martin, R. Mercado, M. W. Deem, D. Gunter, M. Haranczyk, D. S. Sholl, R. Q. Snurr and B. Smit, Energy Environ. Sci., 2015, 8, 1190-1199.

74 F. Guo, Y. Liu, J. Hu, H. Liu and Y. Hu, Phys. Chem. Chem. Phys., 2018, 20, 28193-28204.

75 Y. J. Colón, D. A. Gómez-Gualdrón and R. Q. Snurr, Cryst. Growth Des., 2017, 17, 5801-5810.

76 Y. G. Chung, E. Haldoupis, B. J. Bucior, M. Haranczyk, S. Lee, H. Zhang, K. D. Vogiatzis, M. Milisavljevic, S. Ling, J. S. Camp, B. Slater, J. I. Siepmann, D. S. Sholl and R. Q. Snurr, J. Chem. Eng. Data, 2019, 64, 5985-5998.

77 D. Dubbeldam, S. Calero, D. E. Ellis and R. Q. Snurr, Mol. Simulat., 2016, 42, 81-101.

78 A. K. Rappé, C. J. Casewit, K. Colwell, W. A. Goddard III and W. M. Skiff, J. Am. Chem. Soc., 1992, 114, 10024-10035.

79 H. A. Lorentz, Ann. Phys., 1881, 248, 127-136.

80 D.-Y. Peng and D. B. Robinson, Ind. Eng. Chem. Fundam., 1976, 15, 59-64.

81 D. Frenkel and B. Smit, Understanding molecular simulation: from algorithms to applications, Elsevier, 2001, vol. 1, pp. 269287.

82 B. Widom, J. Chem. Phys., 1963, 39, 2808-2812.

83 F. G. Kerry, Industrial gas handbook: gas separation and purification, CRC press, 2007. 
84 S. M. Auerbach, K. A. Carrado and P. K. Dutta, Handbook of zeolite science and technology, CRC press, 2003.

85 H. Lu, Y. Yan, X. Tong, W. Yan, J. Yu and R. Xu, Sci. China Chem., 2014, 57, 127-134.

86 D. Banerjee, Z. Zhang, A. M. Plonka, J. Li and J. B. Parise, Cryst. Growth Des., 2012, 12, 2162-2165.

87 T. Wang, C. Zhang, Z. Ju and H. Zheng, Dalton Trans., 2015, 44, 6926-6935.

88 G.-L. Zhuang, W.-W. Chen, G.-N. Zeng, J.-G. Wang and W.-L. Chen, CrystEngComm, 2012, 14, 679-683.

89 X. Song, J. Li, Y. Guo, Q. Pan, L. Gan, J. Yu and R. Xu, Inorg. Chem., 2009, 48, 198-203.

90 E. R. Cooper, C. D. Andrews, P. S. Wheatley, P. B. Webb, P. Wormald and R. E. Morris, Nature, 2004, 430, 1012-1016.
91 X. Tong, W. Yan, J. Yu and R. Xu, Chem. Commun., 2013, 49, 11287.

92 S. Chen, S. Hoffmann, Y. Prots, J.-T. Zhao and R. Kniep, Z. anorg. allg. Chem., 2010, 636, 1710-1715.

93 S. Yuan, Y.-K. Deng, W.-M. Xuan, X.-P. Wang, S.-N. Wang, J.M. Dou and D. Sun, CrystEngComm, 2014, 16, 3829.

94 S. C. McKellar, A. J. Graham, D. R. Allan, M. I. H. Mohideen, R. E. Morris and S. A. Moggach, Nanoscale, 2014, 6, 41634173.

95 A. Comotti, S. Bracco, P. Sozzani, S. Horike, R. Matsuda, J. Chen, M. Takata, Y. Kubota and S. Kitagawa, J. Am. Chem. Soc., 2008, 130, 13664-13672.

96 X.-D. Zheng, M. Zhang, L. Jiang and T.-B. Lu, Dalton Trans., 2012, 41, 1786-1791. 